\title{
Modelling stillbirth mortality reduction with the lives saved tool
}

Hannah Blencowe ${ }^{1 *}$, Victoria B. Chou², Joy E. Lawn ${ }^{1}$ and Zulfiqar A. Bhutta ${ }^{3}$

\begin{abstract}
Background: The worldwide burden of stillbirths is large, with an estimated 2.6 million babies stillborn in 2015 including 1.3 million dying during labour. The Every Newborn Action Plan set a stillbirth target of $\leq 12$ per 1000 in all countries by 2030. Planning tools will be essential as countries set policy and plan investment to scale up interventions to meet this target. This paper summarises the approach taken for modelling the impact of scaling-up health interventions on stillbirths in the Lives Saved tool (LiST), and potential future refinements.

Methods: The specific application to stillbirths of the general method for modelling the impact of interventions in LiST is described. The evidence for the effectiveness of potential interventions to reduce stillbirths are reviewed and the assumptions of the affected fraction of stillbirths who could potentially benefit from these interventions are presented. The current assumptions and their effects on stillbirth reduction are described and potential future improvements discussed.

Results: High quality evidence are not available for all parameters in the LiST stillbirth model. Cause-specific mortality data is not available for stillbirths, therefore stillbirths are modelled in LiST using an attributable fraction approach by timing of stillbirths (antepartum/ intrapartum). Of 35 potential interventions to reduce stillbirths identified, eight interventions are currently modelled in LiST. These include childbirth care, induction for prolonged pregnancy, multiple micronutrient and balanced energy supplementation, malaria prevention and detection and management of hypertensive disorders of pregnancy, diabetes and syphilis. For three of the interventions, childbirth care, detection and management of hypertensive disorders of pregnancy, and diabetes the estimate of effectiveness is based on expert opinion through a Delphi process. Only for malaria is coverage information available, with coverage estimated using expert opinion for all other interventions. Going forward, potential improvements identified include improving of effectiveness and coverage estimates for included interventions and addition of further interventions.

Conclusions: Known effective interventions have the potential to reduce stillbirths and can be modelled using the LiST tool. Data for stillbirths are improving. Going forward the LiST tool should seek, where possible, to incorporate these improving data, and to continually be refined to provide an increasingly reliable tool for policy and programming purposes.
\end{abstract}

Keywords: Stillbirths, Lives saved tool, Mortality modelling

\footnotetext{
* Correspondence: hannah.blencowe@lshtm.ac.uk

${ }^{1}$ Maternal Adolescent Reproductive and Child Health (MARCH) Centre,

London School of Hygiene \& Tropical Medicine, G11, Keppel Street, London

WC1E 7HT, UK

Full list of author information is available at the end of the article
}

(c) The Author(s). 2017 Open Access This article is distributed under the terms of the Creative Commons Attribution 4.0 International License (http://creativecommons.org/licenses/by/4.0/), which permits unrestricted use, distribution, and reproduction in any medium, provided you give appropriate credit to the original author(s) and the source, provide a link to the Creative Commons license, and indicate if changes were made. The Creative Commons Public Domain Dedication waiver (http://creativecommons.org/publicdomain/zero/1.0/) applies to the data made available in this article, unless otherwise stated. 


\section{Background}

The worldwide burden of stillbirths is large, with an estimated 2.6 million babies stillborn in 2015 including 1.3 million dying during labour [1]. Stillbirths are an important marker both of maternal health, but also of access to high quality care in pregnancy and particularly around the time of birth [1-3]. These two factors provide an explanation for much of the differences observed in stillbirth rates worldwide, and have received much interest in global health [2-5]. However, despite the large burden and these links to maternal health and quality of care, stillbirths are not included in routine global monitoring $[1,6]$. Failure to count stillbirths ignores their impact on women, families and society, underestimates the benefits of investments in maternity care, and has led to failure of investment to reduce stillbirth numbers $[5,7,8]$.

Some evidence of increased recognition of the importance of stillbirths on a global level has been seen recently with stillbirths included in the 2014 Every Newborn Action Plan (ENAP) to end preventable deaths of newborns, mothers and stillbirths, and as a core indicator in the Global Strategy on Women's Children's and Adolescent Health [9, 10]. Improved stillbirth data collection will be essential to allow tracking of progress towards the ENAP stillbirth target of $\leq 12$ per 1000 by 2030, and Global Strategy tracking of the stillbirth and linked indicators for the Sustainable Development Goals 3.1 and 3.2. However, in addition to these improved data, tools such as the Lives Saved Tool will be essential to help countries set policy and plan investment to scale up interventions to meet the national ENAP stillbirth target.

The Lives Saved Tool (LiST) is an evidence-based software tool used to model the impact of scaling-up health interventions aimed to reduce mortality and morbidity in mothers, newborns, and children under five years of age and stillbirths. The framework has continued to evolve since the original Lancet 2003 child survival series examined the impact of increasing coverage of proven child health interventions, and the model has expanded to include further interventions and outcomes as the need for such a tool to help guide policy and program planning became evident $[11,12]$. LiST has been adopted by diverse stakeholders, and can be integrated into and strengthen existing planning processes.

Stillbirths were added as an outcome to the LiST model in 2011. The 2011 supplement in BMC Public Health published 7 papers on the impact of interventions on the risk of stillbirth for pregnant women [13-19], and an overview of the modelling approach was included in the original Lancet Stillbirth Series [20]. The interventions included in these publications describe the scientific underpinning of the LiST-based estimates for stillbirth reduction reported in the Lancet Stillbirth Series 2011,
Lancet Every Newborn Series in 2014 and Lancet Ending Preventable Stillbirths Series 2016 [8, 21, 22]. However, the modelling of stillbirths has evolved during this period, in response to the changing evidence landscape with the suite of interventions modelled varying over time. In this paper we present an overview of the currently included interventions, data inputs and assumptions underlying the existing LiST model for the impact of scaling-up health interventions on stillbirths. Where relevant, details about changes which have occurred over time and potential refinements for future versions are presented.

\section{Methods}

\section{Theoretical approach and basic modelling structure of LiST}

The modelling structure and underlying theory of change of the LiST model has been described in detail in previous publications [23]. Briefly, LiST is a linear, mathematical deterministic model with fixed relationships between inputs (coverage of interventions) and outputs (changes in cause-specific mortality or population-level risk factors for mortality such as intrauterine growth restriction (IUGR)) [24]. Its framework is based upon demographic details, cause of death information, coverage indicators and intervention effectiveness estimates (Table 1). It assumes that mortality rates and the cause of death structure will not change dynamically, and that any differences in the outcomes will be attributable to the change in coverage of key interventions.

LiST allows users to set up and run multiple scenarios, called projections, in order to estimate the impact of different health intervention packages based upon coverage at the national or subnational (e.g. region, state, or district) level. These projections provide a structured format for program managers or ministry of health personnel to utilize the latest scientific information about the effectiveness of interventions for maternal, neonatal, and child health; combine information about causes of death and current coverage of interventions to inform planning and decision-making, and help prioritize investments and evaluate existing programs. Currently, there are approximately 60 interventions amenable to scale-up in low and middle income settings in the short to medium term that are categorized across the continuum of care which impact mortality and morbidity outcomes for specific population subgroups (e.g. stillbirths, neonatal, child-under 5, or maternal deaths) or risk factors (e.g. stunting and wasting) modelled in LiST.

Work to review and estimate the cause-specific effects for interventions was previously led by the Child Health Epidemiology Reference Group (CHERG) of the World Health Organization (WHO) and UNICEF following established standard practices and guidelines using an 
Table 1 Framework of the Lives Saved Tool

\begin{tabular}{ll}
\hline Parameter of the Lives Saved Tool & Source of Data \\
\hline Demography details (e.g. total population, fertility) & $\begin{array}{l}\text { Demographic projections produced by the United Nations Population Division } \\
\text { or derived from national or subnational demographic estimates }\end{array}$ \\
$\begin{array}{ll}\text { Cause of death information from country-specific WHO profiles or } \\
\text { estimated by using local data sources }\end{array}$ & $\begin{array}{l}\text { Country-specific profiles produced by Maternal and Child Epidemiology } \\
\text { Estimation (MCEE) group or estimated based upon local data sources }\end{array}$ \\
$\begin{array}{ll}\text { Coverage levels for a variety of key health interventions that affect } \\
\text { child and maternal mortality }\end{array}$ & $\begin{array}{l}\text { Nationally representative household surveys, such as Demographic and } \\
\text { Health Surveys (DHS) and Multiple Indicator Cluster Surveys (MICS), or }\end{array}$ \\
$\begin{array}{ll}\text { local data sources (e.g. annual state surveys or program data) } \\
\text { Health status indicators for a national or subnational setting }\end{array}$ & $\begin{array}{l}\text { Nationally representative household surveys, such as Demographic and } \\
\text { Health Surveys (DHS) and Multiple Indicator Cluster Surveys (MICS), or } \\
\text { local data sources (e.g. annual state surveys or program data) } \\
\text { Cochrane reviews, meta-analyses, Delphi studies, and scientific literature }\end{array}$ \\
$\begin{array}{l}\text { Effectiveness estimates for stillbirth, maternal, neonatal, and child } \\
\text { interventions }\end{array}$ &
\end{tabular}

adapted GRADE approach [25]. Consistent with this approach, where evidence from trials or observational studies were not available for a given intervention, an expert Delphi process was undertaken to determine an effect estimate. Data from low and middle income settings were used where possible. Baseline coverage data were based on the latest nationally representative household surveys where available and where such data were not available, expert opinion from the neonatal and stillbirth leads (ZB and JEL) was used to estimate coverage. Oversight and recommendations continue to be led by global health experts organized into technical working groups around a specific area of expertise (e.g. nutrition) which meet on an ad hoc basis to highlight areas for future work and refinements to strengthen the model. Implementation of changes and overall development of the LiST model continues to be led and managed by the Institute for International Programs at the Johns Hopkins Bloomberg School of Public Health.

\section{Modelling stillbirths in LiST}

Special considerations exist when modelling stillbirths in LiST compared to other maternal-child outcomes, in large part due to lack of reliable and routinely collected data related to stillbirths in many data platforms. Stillbirths are modelled independently in LiST compared to other maternal-child outcomes. The overall envelope for the estimated total number of stillbirths at $\geq 1000$ g or $\geq 28$ weeks (third trimester or late fetal deaths) in a country are obtained from WHO estimates [26]. However, in contrast to many other maternal-child outcomes, standard definitions of stillbirth are not universally applied across intervention studies. Hence, it is sometimes necessary to assume that the reductions in mortality for specific interventions that have been reported using a wider definition, e.g. fetal deaths $\geq 22$ weeks or even 'all fetal losses regardless of gestation', would also apply to stillbirths at $\geq 28$ weeks.
In addition, systematic estimates of cause of death for stillbirths are not available, therefore stillbirths are modelled using a simple classification based upon timing of stillbirth - antepartum (prior to the onset of labour) or intrapartum (fetal death during labour, but prior to full extraction from the mother). Whilst this is commonly used from a programmatic perspective, even the underlying data to produce country-level estimates according to this dichotomy of stillbirth timing are very sparse, with estimates of the proportion of stillbirths that are intrapartum being based upon a regional median approach for most countries [1] .

Therefore, whereas for maternal deaths, and child deaths following a livebirth, estimates of efficacy or effectiveness to reduce cause-specific mortality (rather than overall mortality) can be used, this is not possible for stillbirths. Stillbirths lack cause of death information and therefore, neither estimates for the envelope of the number of stillbirths from a specific cause, or interventionbased cause-specific mortality changes can be estimated.

An overview of the modelling approach for stillbirths in LiST is shown in Fig. 1. Any given intervention can have an effect on antepartum or intrapartum stillbirths, or both. The effectiveness of the intervention is derived based on published evidence. Where no published evidence is available for an intervention, the estimate of effectiveness is obtained through expert opinion (see below for specific details). In LiST to calculate the number of stillbirths averted, the estimate of effectiveness is multiplied by the change in coverage. For example, if syphilis detection and treatment is $82 \%$ effective in reducing antepartum stillbirths attributable to syphilis, but none of a given population has access to this intervention at baseline, an increase in coverage to $50 \%$ is estimated to avert: $82 \% \mathrm{X}(50 \%-0 \%)=41 \%$ of all antepartum stillbirths attributable to syphilis.

Some interventions have limited effectiveness so modelled impact is restricted to a sub-group of all deaths. This 


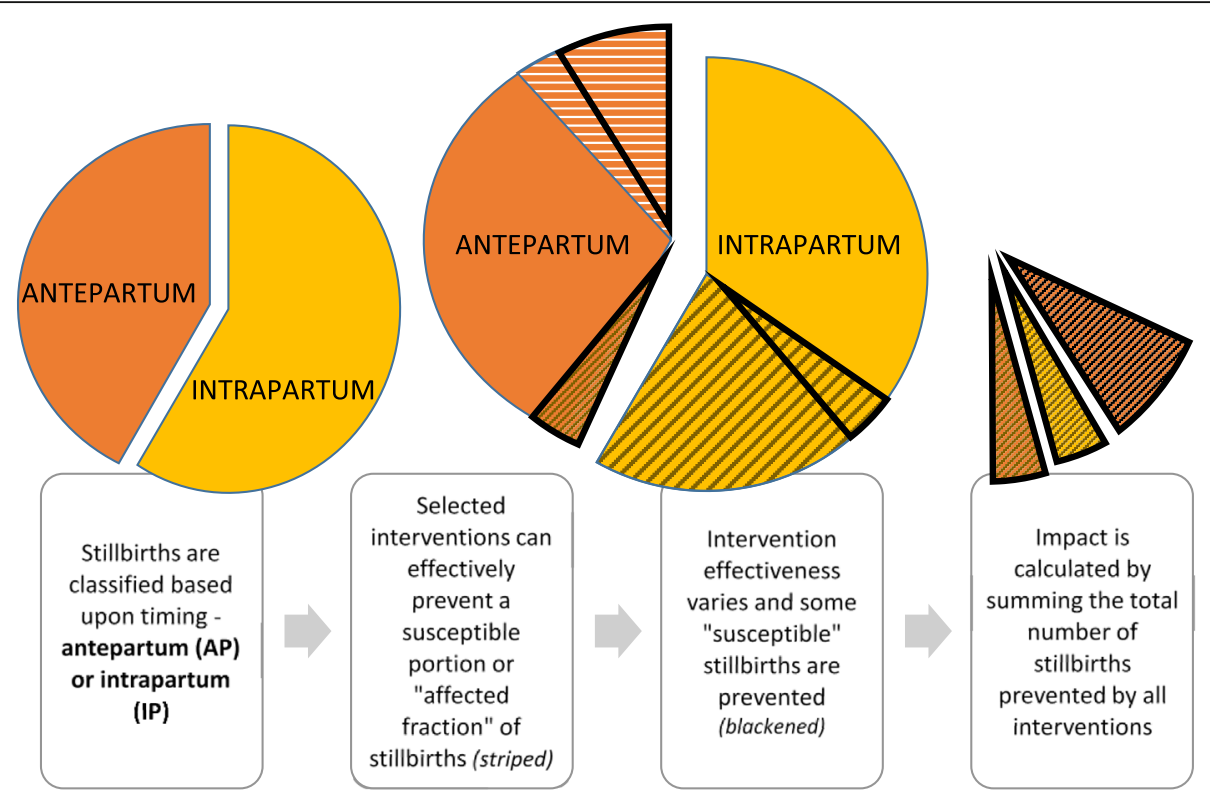

Fig. 1 Overview of modelling approach for stillbirths in the Lives Saved Tool

'affected fraction' is defined in LiST as the proportion of the cause-specific mortality, here antepartum or intrapartum stillbirths, that is considered susceptible to that intervention. Where possible this is calculated as the intrapartum or antepartum stillbirths attributable to the underlying cause in the population based on the prevalence of the risk factor and the increased risk of stillbirth among women exposed to the risk factor (see Additional file 1). If an estimate of increased stillbirth risk is not known for any risk factor, the risk of stillbirth remains the same in those with the exposure as the general population, and hence will underestimate the affected fraction.

For example, balanced energy supplementation has evidence of a $40 \%$ reduction in antepartum stillbirths in food-insecure households, but no effect on stillbirths in other households. The number of stillbirths averted is calculated as the estimate of effectiveness multiplied by the coverage multiplied by the 'affected fraction'. If $20 \%$ of a population are food insecure and the coverage was increased from 0 to $50 \%$ of food insecure households the estimated number of stillbirths averted would be: $40 \% \mathrm{X}$ $(50 \%-0 \%)$ X $20 \%=4 \%$ of all antepartum stillbirths.

\section{Interventions to reduce stillbirths}

As a first step in defining potential interventions to reduce stillbirths, a conceptual framework of previously identified risk factors for stillbirths can be used (Fig. 2) [1, 27-29]. It should be noted that many of the pathways to stillbirth, particularly antepartum stillbirths, remain inadequately understood, however, for the purposes of this work we are interested in currently modifiable factors. Based on this conceptual framework, a list of potential interventions along the continuum of care from preconception through childbirth care to address these factors, and hence reduce stillbirth mortality, can be considered. Potential interventions of interest were selected on the basis of clear or potential evidence of benefit to reduce stillbirth. Interventions relevant to public health policy, such as those with a large impact on stillbirth reduction that are amenable to scale-up in low and middle income settings in the short to medium term are prioritised. The LiST model currently includes a total of eight interventions that have an impact on stillbirth mortality (Fig. 3). The included interventions have been revised over time (Table 2).

\section{Results}

Summary of included interventions to reduce stillbirth

Of the many possible modifiable underlying causes and risk factors for stillbirth, evidence of scale-able interventions with potential public health effect are only available for a subset. Systematic reviews undertaken prior to the inclusion of stillbirths in LiST in 2011 identified 35 potential interventions, of which 10 were strongly recommended by the technical working group for inclusion in LiST. Since that time two interventions, folic acid supplementation and fetal growth restriction detection and management have been removed, and two new nutritional interventions have been added. Table 2 contains a summary of the interventions modelled within LiST, including the dates that these were included in or removed from the model. Details of the sources of estimates of intervention effects, affected fraction and 


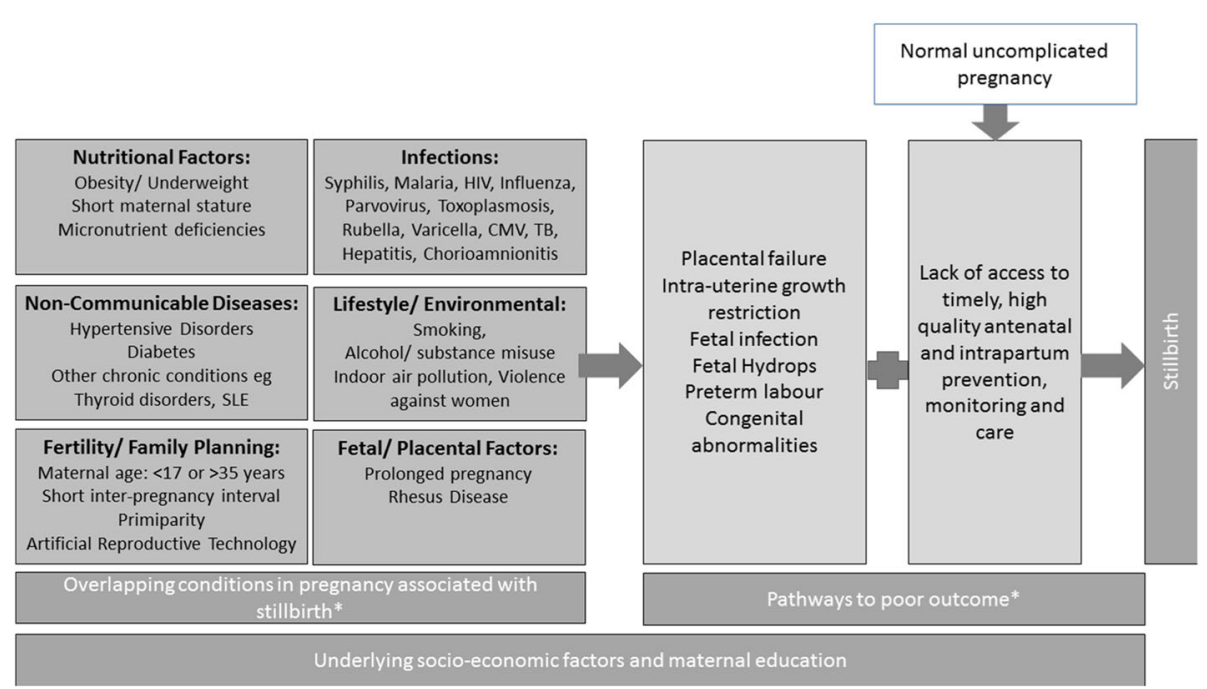

Fig. 2 Conceptual framework for known pathways to stillbirth. * This conceptual framework focuses on known conditions in pregnancy associated with stillbirth and understood pathways to stillbirth which are potentially amenable to interventions. The underlying causes and factors in many stillbirths remain unknown, this framework should be revised as further evidence becomes available

coverage are provided in Table 3 and Additional file 1, with details described below for each intervention. Further details about the quality of the evidence of effectiveness for the included interventions can be found in Additional file 2. More detailed descriptions of the currently included interventions are provided below:

\section{Preventative interventions before and during pregnancy Supplementation with micronutrients before and during pregnancy}

Micronutrient deficiencies are common amongst pregnant women and are associated with fetal growth restriction and congenital abnormalities, which can both increase the risk of stillbirth.

Haider et al. found a 9\% reduction in all-cause stillbirths with micronutrient supplementation during pregnancy compared to iron with or without folic acid (15 RCTs $n=98,808 \mathrm{RR}=0.92,95 \%$ CI 0.86 to 0.99 ) [30]. Folic acid has previously been shown to have a protective effect to reduce neural tube defects, which are associated with an increased risk of stillbirths, especially when severe [31]. Up until 2016, the effect of folic acid was included in the LiST model for stillbirths (see Additional file 2). This assumed that fortification and supplementation with folic acid were interchangeable. However, whilst the evidence for the effect of folic acid fortification is increasing [32], there is currently no evidence to support an effect of folic acid supplementation, which requires starting periconceptually, on all-cause stillbirth mortality (4 trials $(n=6597) \mathrm{RR}=1.05$ (95\% CI 0.54 to 2.05$)$ and therefore the intervention was removed from the LiST model [33] .

No evidence of an effect of Vitamin A, C, D or E, or zinc, magnesium or calcium supplementation on stillbirth reduction has been found in recent Cochrane reviews [34-40], and only the effect for micronutrient supplementation is currently included in the LiST model for

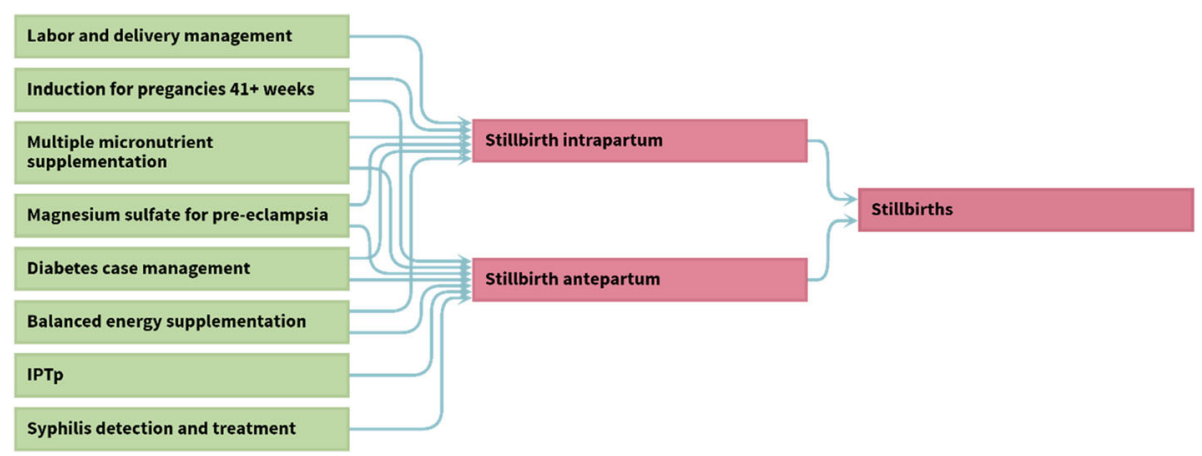

Fig. 3 Interventions included in Lives Saved Tool model which impact on stillbirths by timing (antepartum/ intrapartum). This schema represents the LiST modelling of stillbirths as of September 2016 
Table 2 Summary of interventions effecting stillbirths included in the Lives Saved Tool 2011-2016 ${ }^{\text {a }}$

\begin{tabular}{|c|c|c|c|c|}
\hline Period & Intervention & Antepartum Stillbirths & Intrapartum Stillbirths & Current status \\
\hline Periconceptual & Folic acid supplementation/ Fortification & $x$ & $x$ & $\begin{array}{l}\text { Not included. Included in previous versions } \\
\text { to Feb } 2016\end{array}$ \\
\hline Pregnancy & Multiple micronutrient supplementation & $x$ & $x$ & New intervention added in Feb $2016^{b}$ \\
\hline Pregnancy & Malaria prevention with ITp or ITN ${ }^{c}$ & $x$ & & Included since 2011 \\
\hline Pregnancy & Balanced energy supplementation & $x$ & $x$ & New intervention added in Feb 2016 \\
\hline Pregnancy & Syphilis detection and treatment & $x$ & & Included since 2011 \\
\hline Pregnancy & Diabetes case management & $x$ & $x$ & Included since 2011 \\
\hline Pregnancy & $\begin{array}{l}\text { Management of hypertensive disorders } \\
\text { of pregnancy }\end{array}$ & $x$ & $x$ & Included since 2011 \\
\hline Pregnancy & $\begin{array}{l}\text { Fetal growth restriction detection and } \\
\text { management }\end{array}$ & $x$ & $x$ & $\begin{array}{l}\text { Not included. Included in previous versions } \\
\text { to May } 2015\end{array}$ \\
\hline Childbirth & Labour and delivery management & & $x$ & Included since 2011 \\
\hline Childbirth & $\begin{array}{l}\text { Induction of labour for pregnancies } \\
\text { lasting }>41 \text { weeks }\end{array}$ & $x$ & $x$ & Included since 2011 \\
\hline
\end{tabular}

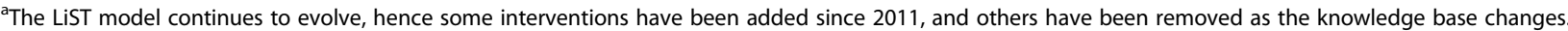
The final column provides details of the current status in version 5.45 (Sept 20 2016)

${ }^{\mathrm{b}} \mathrm{New}$ evidence from the updated Cochrane suggests that there is no effect of multiple micronutrient supplementation on stillbirths (RR 0.97, 95\% Cl 0.87-1.09) and this effect and it is likely that the technical working group will recommend that the effect is removed in subsequent LiST revisions

Intervention is labelled as IPTp (Intermittent prophylaxis and treatment of Malaria in pregnancy), or ITN (insecticide treated bednets), although the effectiveness estimate is from ITN alone
}

stillbirths (see footnote Table 2). The estimate of effect for micronutrient supplementation is for all pregnant women, and hence the affected fraction is 1.0 for both antepartum and intrapartum stillbirths. As coverage of micronutrient supplementation during pregnancy is generally very low, the default for baseline coverage of this intervention in LiST is $0 \%$ in all settings (Table 2). It should be noted that in all these micronutrient studies, the number of included cases is relatively low, and as such they may have been under-powered to detect a true effect, especially if the effect size or the affected fraction (on which the intervention may have an effect) is small. However, in these cases, it is less likely that increasing coverage of these interventions at a population level would have a substantial impact on stillbirths in a country.

\section{Balanced energy supplementation}

Maternal undernutrition is associated with poor fetal growth, low birthweight, and increased risk of stillbirth [41]. Balanced energy supplementation was found to reduce all-cause stillbirths by $40 \%$ in food-insecure households (5 RCTs 3408 women. (RR 0.60, 95\% CI 0.39 to 0.94)) [42]. The proportion of the population living on $<\$ 1.90 /$ day from World Bank is used as the affected fraction, to approximate food-insecure households [43]. It is assumed that this proportion is equal to the proportion of stillbirths occurring in food-insecure households, i.e. that the stillbirth rate in food-insecure is the same as that in insecure households. This is likely to be a conservative estimate, as stillbirth rates may be higher in food-insecure households, where other risk factors for stillbirths are likely to co-exist. It is assumed that the baseline coverage in LiST for this intervention is $0 \%$ in all settings.

\section{Prevention of malaria in pregnancy}

It is estimated that over 125 million pregnant women are at risk of malaria each year, with pregnant women at risk of more severe disease, and their fetus is vulnerable due to effects of maternal systemic febrile illness, impaired placenta function due to placental infection, or the more rare condition of direct fetal infection [44]. Malaria is hence an important cause of stillbirth in countries where malaria is endemic, and is estimated to be attributable for around $20 \%$ of stillbirths in sub-Saharan Africa. There is moderate evidence of the effectiveness of insecticide-treated bednets (ITNs) to reduce all-cause fetal loss (stillbirths and miscarriages at all gestational ages) for women during their first and second pregnancies (3 cRCTs (RR 0.67, 95\% CI 0.47 to 0.97)) $[18,45]$. No significant effect of intermittent preventative treatment in pregnancy (IPTp) to prevent all-cause stillbirths was found in a recent Cochrane review (5 RCTs, 7130 women. RR 1.02, 95\% CI 0.76 to 1.36. Moderate quality evidence) [46] .

In LiST, the affected fraction to which this effect estimate is currently applied represents stillbirths attributable to falciparum malaria. Although initially it was planned that impact would be calculated assuming that only women in their 1st or 2nd pregnancies were at increased risk of stillbirth, currently the estimate includes stillbirths attributable to malaria 


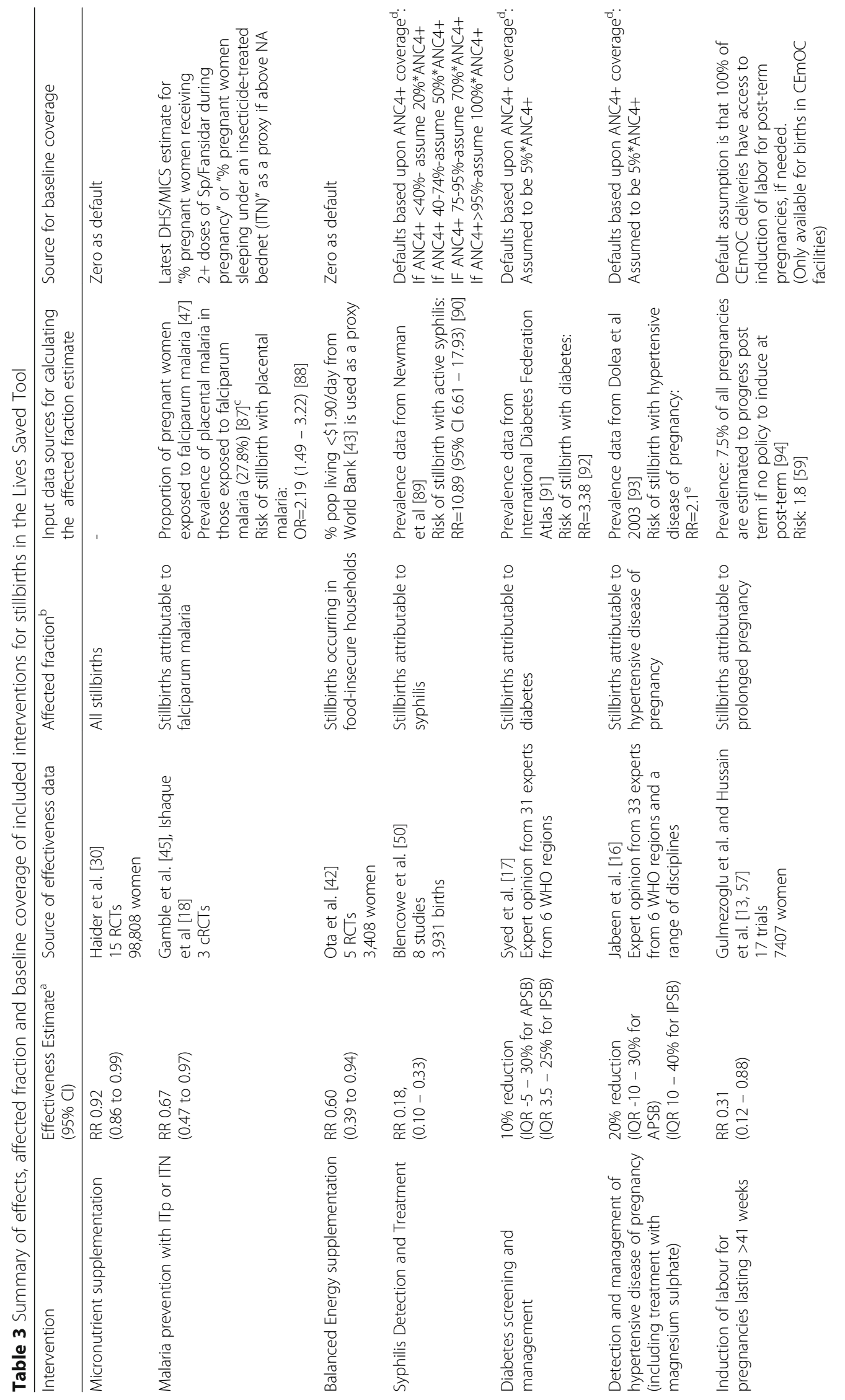




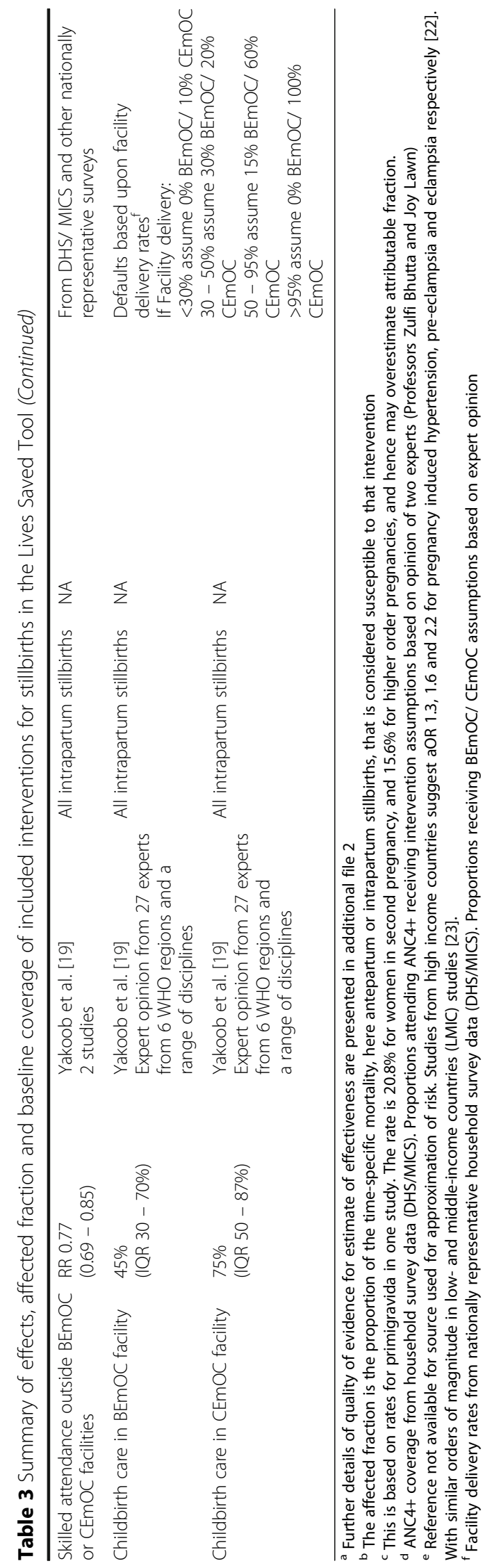


regardless of parity [47] (Table 2). On a country-level, both ITNs and IPTp are used in combination in endemic populations and currently in LiST, the effect of ITNs is also assumed to apply to women using IPTp. Therefore, the baseline coverage for ITNs is estimated from the latest household survey data for "\% pregnant women receiving $2+$ doses of $\mathrm{Sp} /$ Fansidar during pregnancy", or "\% pregnant women sleeping under an insecticide-treated bednet (ITN)" if the former is not available.

\section{Detection and management of conditions in pregnancy Syphilis case management}

In 2012, there were an estimated 930,000 maternal syphilis infections worldwide, leading to 350,000 adverse pregnancy outcomes including 143,000 early fetal deaths and stillbirths [48]. Maternal syphilis infection is able to cross the placenta and infect the fetus in-utero, which can lead to multi-organ damage or congenital developmental abnormalities, hence pregnant women with untreated syphilis infection have $21 \%$ higher rates of fetal loss or stillbirth compared to uninfected women [49].

Detection and treatment of syphilis during pregnancy is estimated to reduce all-cause stillbirths by $82 \%$ ( 8 studies, 3931 births. RR $0.18,95 \%$ CI 0.10 to 0.33 ) [50]. Only stillbirths in women with untreated syphilis could potentially benefit from this intervention. The affected fraction is therefore calculated as the proportion of cases in the whole population that may be attributed to the exposure (untreated syphilis), (see Table 3, Additional file 1). This effect estimate is currently applied only to antepartum stillbirths.

No robust country-level data for the current (baseline) coverage of detection and treatment of syphilis in pregnancy are available for all countries modelled in LiST. Testing and treatment of pregnant women is undertaken during antenatal care visits. As a minimum of two visits is usually required, one to take the blood test and the second to receive the result and get the treatment, it is assumed that a sub-set of those attending full antenatal care $(\mathrm{ANC4}+)$ will receive the intervention. Currently, in LiST, it is assumed that a proportion of women attending all four ANC visits in a country will receive testing and treatment for syphilis, and that none receiving fewer than 4 visits will receive such services. These levels were defined by expert opinion, assuming that coverage of the intervention increases with coverage of four ANC visits, for example where ANC4 coverage is low (<40\%) only $20 \%$ of those attending will receive testing and treatment (Table 3). A limitation of this approach is that the national level ANC4+ coverage is likely to overestimate the coverage in women with syphilis who, due to socio- economic factors, are less likely to access such care than the general pregnant population. Work is currently underway to examine the validity of these coverage proxy assumptions in LiST, and to propose methods to improve these coverage estimates.

\section{Diabetes case management}

The global epidemic of obesity is affecting pregnancies worldwide [51], with increasing prevalence of type II diabetes in women of reproductive age and gestational diabetes across all regions $[52,53]$.

Pregnancies affected by gestational diabetes have a higher risk of perinatal mortality than unaffected pregnancies [54], and pregnant women with pre-existing type I or II diabetes are at increased risk of stillbirth even in high income countries (RR 2.9, 95\% CI 2.05 to 4.09) [55] .

A review undertaken in 2011 was unable to provide an appropriate effect estimate for the overall package of diabetes detection and management in pregnancy, and hence the effect estimate recommended by the technical working group was based on a Delphi process for expert opinion [17]. This estimated a $10 \%$ reduction in diabetic-related stillbirth with diabetes screening and management versus no specific identification or care for women with diabetes [17]. The affected fraction that could potentially benefit from this intervention are stillbirths attributable to diabetes (Table 3). No robust country-level data for the current (baseline) coverage of diabetes screening and management were available. In general, coverage of this intervention is thought to be low and it was therefore assumed, based on expert opinion, that only a small minority (5\%) of women accessing 4 or more ANC visits would be receiving this intervention. In practice, this is likely to vary by setting and local policy.

\section{Hypertensive disorders of pregnancy case management}

Hypertensive disorders of pregnancy, including pregnancy induced hypertension, pre-eclampsia and eclampsia, are common complications which occur and approximately $6 \%$ of pregnancies are affected by its more severe forms (e.g., pre-eclampsia and eclampsia) [56]. In high-income countries where early detection is possible, women with either pre-eclampsia or pre-eclampsia have approximately double the risk of stillbirth or neonatal death compared to unaffected women [55]. The risks are likely to be higher in low-resource settings with limited access to detection, and management which may include emergency caesarean section.

The risk is highest for those affected by the more severe forms of hypertensive disorders, and hence currently in LiST the effect of intervention is modelled only for these two more severe conditions.

No suitable evidence was found for a package of interventions for the management of pre-eclampsia and 
eclampsia, and hence the effect estimate recommended by the technical working group for this intervention was based on a Delphi process for expert opinion. This process suggested a $20 \%$ reduction in antepartum and intrapartum stillbirths in women with pre-eclampsia and eclampsia with a package of management interventions including antihypertensive, magnesium sulphate and C-section if needed [16]. The affected fraction is stillbirths attributable to pre-eclampsia or eclampsia (see Table 3). Similar to the case for diabetes, no robust country-level data for the current (baseline) coverage of hypertensive disorders management were available, and coverage of this is thought to be low so it was therefore assumed, based on expert opinion, that only 5\% of women accessing 4 or more ANC visits would be receiving this intervention.

There is currently insufficient evidence to estimate the effect of potential interventions including calcium supplementation (see micronutrient interventions above) or aspirin $[16,35]$ to prevent hypertensive disorders of pregnancy.

\section{Prolonged pregnancy case management}

Pregnancies lasting longer than around 42 weeks are associated with an increased risk of placental failure and stillbirth. An estimated 14.2\% of stillbirths worldwide are attributable to prolonged pregnancy [1]. Induction of pregnancy is an effective method to prevent adverse pregnancy outcomes. A recent Cochrane review was underpowered to detect an effect on stillbirth reduction with induction of pregnancy at 41 completed weeks or more versus expectant management (17 trials, 7407 women. RR $0.30,95 \%$ CI 0.08 to 1.08 ), however the review found a $69 \%$ reduction in perinatal deaths (17 trials, 7407 women. RR $0.31,95 \%$ CI 0.12 to 0.88$)[13,57]$. The effect on all cause perinatal mortality is used for the estimate of effectiveness in LiST. This risk data is consistent with population-based data from Denmark, where the risk of fetal death after 42 weeks was reduced by 30 $33 \%(p<0.05)$ with induction of labour for prolonged pregnancy [58].

The affected fraction that could potentially receive benefit from this intervention are stillbirths attributable to prolonged pregnancy. Gulmezoglu et al. estimate that $7.5 \%$ of all pregnancies progress beyond term [57]. The increased risk of stillbirth in post-term pregnancies currently used in LiST is RR 1.8 [59] (Table 2).

Caution however is required prior to consideration of scale-up of this intervention. In the absence of both widespread availability of accurate dating of pregnancies through early ultrasound and safe emergency obstetric care, there is real potential for harm to women and their babies through increased risk of caesarean section and iatrogenic late preterm or early term (37 weeks gestation) birth in cases of mistaken gestational age [60]. For this reason, coverage of this intervention is capped by default to equal coverage or the proportion of births occurring at Comprehensive Obstetric Care (CEmOC)level facilities.

\section{Childbirth care}

All pregnant women need access to appropriate childbirth care, including skilled birth attendance, and timely access to Basic Emergency Obstetric Care (BEmOC) or Comprehensive Obstetric Care (CEmOC) if complications arise [61]. Higher coverage of birth with a skilled attendant is strongly associated with lower intrapartum stillbirth rates [1, 62]. Similarly, higher coverage of caesarean section up to rates of $10 \%$ are associated with sharp reductions in stillbirth rates, although no benefit of higher rates is seen [63].

\section{Skilled attendance outside BEmOC or CEmOC facilities}

All cause stillbirths were estimated to be reduced by 23\% (RR 0.77. 95\% CI 0.69 to 0.85 ) for women who delivered at home/outside $\mathrm{BEmOC}$ or CemOC facilities with a skilled birth attendant based on a meta-analysis of 2 before and after studies [19]. A similar estimate of $25 \%$ reduction was obtained from a Delphi process [19].

\section{Childbirth care in BEmOC or CEmOC facility}

A systematic review of the impact of skilled birth attendance and Emergency Obstetric Care found insufficient evidence from randomised trials or robust quasiexperimental designs to provide an estimate of effect for Emergency Obstetric Care. The estimates of effect for these interventions were therefore obtained through a Delphi expert opinion process [19] which determined that 45 and $75 \%$ of intrapartum stillbirths could be prevented by universal access to BEmOC and CEmOC respectively, compared to home delivery without a skilled attendant.

For all of these childbirth care interventions, the affected fraction is all intrapartum stillbirths. The coverage of these three packages of care is interconnected - with the sum of coverage for each of the three packages, plus those delivering at home without a skilled attendant, summing to $100 \%$. The baseline coverage of skilled birth attendance is drawn from data collected during recent household surveys. No suitable data are available to estimate the coverage of emergency obstetric care packages, and hence the baseline estimates of coverage are based upon expert opinion, which assumes a relationship between level of facility delivery and the proportion of women able to access emergency obstetric care packages at those levels of care (Table 2). 


\section{Discussion}

In this section we provide details about the limitations of the current approach, alongside details of other potential refinements to strengthen the modelling of the effects of interventions on stillbirths in LiST to further improve its utility to policy makers and program managers.

\section{Limitations of current approach and recommendations for future improvements}

Underlying data to support modelling and estimation for stillbirths are not as strong as for other maternal-child outcomes. Advances have been made in the overall quantity of data to inform country-level estimates of overall stillbirth rates, however as stillbirth and neonatal deaths are modelled independently as separate outcomes within LiST, misclassification between intrapartum stillbirth and early neonatal death, thought to remain common in low-resource settings, may potentially effect the accuracy of the estimates [26]. In addition, the quality of data available to inform the breakdown of stillbirths by timing (antepartum/ intrapartum) remains low [1]. Prevalence data used to calculate the attributable stillbirth mortality currently included are generally based on single time-point data that were available around the year 2010. Since this time, an increase in the measurement and reporting of prevalence data, coupled with improvements in estimation techniques have resulted in improved country-level estimates which could be incorporated into future LiST versions.

The prevalence of specific exposures and stillbirth risk factors may be expected to vary over time in a given country but data are not available to reliably track these trends over time. For most interventions in LiST, these factors are assumed to remain static when estimating maternal, neonatal, or child outcomes with the exception of certain pathogen-related illnesses (e.g. diarrheoa, pneumonia, and meningitis) which shift as certain interventions are scaled up and the etiological burden changes accordingly.

Issues that have been identified with the application of some effect estimates (e.g. folic acid supplementation and fetal growth restriction) have now been addressed. However, data underpinning the effectiveness estimates remains sparse for some interventions. In some cases, effectiveness data must be drawn from trials conducted in high-income countries and in others, where the conduct of randomized controlled trials (RCTs) would not be ethical, estimates are derived from expert opinion.

In addition to this, effectiveness estimates, apart from childbirth care, remain broadly applicable to all stillbirths, and are not time-specific (antepartum/ intrapartum). The current approach assumes that this estimate of affect is equally applicable to all 'affected' antepartum stillbirths and intrapartum stillbirths, apart from for syphilis detection and treatment and malaria prevention. However, in practice this is unlikely for many conditions. For example, the effect of micronutrient supplementation is likely to primarily effect antepartum stillbirths. A future approach could consider modelling all stillbirths together and for childbirth care interventions, the percentage of intrapartum stillbirths could be applied as the affected fraction. However, a limitation of this is that the number of averted stillbirths split by timing (antepartum versus intrapartum) would no longer be available to guide policy makers. Further research is required to understand how widespread the use of these data are by programs and policy makers.

Reliable population-based coverage data are not available for many interventions. LiST has therefore relied on expert opinion to estimate likely levels of coverage for interventions using different levels of coverage reported for antenatal and childbirth care as a proxy. The current assumptions create a step-like increase in coverage for some interventions, such as the detection and management of syphilis and childbirth care, whilst very low coverage is assumed for others, such as the detection and management of diabetes and hypertension, even at high ANC4 coverage (see Additional file 3: Figures S1 and S2). New evidence is emerging and may help to inform these coverage assumptions. For example, national estimates of coverage for testing and treatment for syphilis during pregnancy are now available and reveal poor correlation with ANC4 coverage (see Additional file 3: Figure S3) [48]. Work is underway to review currently available evidence to guide these coverage estimates and refine these assumptions in future versions of LiST.

Quantification to estimate the number of lives saved involves some degree of uncertainty. This uncertainty has not been quantified up to now, however initial work has been completed to provide an accompanying range of upper and lower bounds for all model outcomes. In future versions of LiST where these ranges are standard outputs, parameters which would influence the uncertainty ranges for stillbirth outcomes include the effectiveness of stillbirth interventions, stillbirth rates, and the proportion of stillbirths that occur antepartum versus intrapartum. After adequate rounds of beta testing, uncertainty estimates will be available as ranges for stillbirth rates, the number of stillbirths, and the number of stillbirths prevented as estimated by LiST. A full description of the model's methodology for uncertainty and sensitivity analysis is forthcoming and will be presented in a peer-reviewed publication.

\section{Updates to effectiveness data for currently reviewed interventions}

We undertook a review of the existing literature for the included interventions and searched for any newer 
evidence published after the previous reviews. No subsequent publications relating the estimate of effect for detection and treatment of syphilis, childbirth care or management of prolonged pregnancy were found.

For detection of fetal growth restriction, a new review found no evidence of benefit for perinatal mortality with symphysis fundal height and serial ultrasound scans compared to clinical palpation alone (1 study. 1639 women. RR 1.25, 95\% CI 0.38 to 4.07) [64]. A further new review also found no evidence for biochemical tests of placental function on perinatal mortality ( 2 trials. 740 women. RR 0.88 , 95\% CI 0.36 to 2.12) [65]. However, potentially more promising as an intervention to prevent stillbirth is the possible effectiveness of detection and monitoring of women at high-risk of fetal growth restriction [66]. This should be considered for inclusion in future versions of LiST if further evidence applicable to the low and middle income setting becomes available.

There has been a proliferation of studies examining interventions to improve outcomes for diabetes, particularly gestational diabetes, and hypertensive disorders of pregnancy. A full update is now warranted and the previously undertaken systematic reviews on this topic would be bolstered by adding further evidence to support the effect estimate used in LiST [16, 17].

\section{Evidence to support the addition of other potential interventions to prevent stillbirths}

Whilst a plethora of evidence summaries have been published in the last 5 years relating to interventions during pregnancy which may improve stillbirth outcomes, the majority of these studies found no evidence of effect or pertain to interventions which could not be readily scaled-up in low resource settings. In the future it would be desirable to improve the utility of the LiST tool for stillbirths by expanding the tool to include additional interventions targeting major risk factors for or causes of stillbirth. Below we detail some candidate interventions for possible inclusion:

\section{Fetal growth restriction case management}

Fetal growth restriction, which is frequently due to placental dysfunction, is a common final pathway leading to stillbirth in many cases (Fig. 2). Reliable detection of a fetus whose growth is faltering can allow close monitoring and timely induction of labour or caesarean section prior to fetal death. A package for screening which relies upon body-mass-index (BMI), fundal height and targeted ultrasound scan with appropriate management was estimated by Delphi expert consensus to reduce antepartum and intrapartum stillbirths in high risk pregnancies by $20 \%$ [15]. This effect would require the availability of specialised obstetric services including serial ultrasound scans and caesarean section if needed, which are not routinely available in many settings. This effect was included in the LiST model from 2011 to 2016. However, it is currently not included as both the screening package and potential effectiveness in different settings is poorly defined.

\section{Nutritional interventions}

The last few years have seen the increasing roll out of folic acid fortification to prevent folate-sensitive neural tube disorders [67]. Although previous versions of LiST included an estimate of effect for folic supplementation, research has shown supplementation to be an ineffective strategy, because in most cases, even when taken, supplements are not taken peri-conceptually, and hence started too late to be effective to prevent neural tube defects and associated stillbirths. Folic acid fortification is estimated to reduce primary neural tube defects by $41 \%$ (11 studies. RR $0.59,95 \%$ CI 0.52 to 0.68 ) [14], and assuming fortification does not alter the spectrum of the severity or stillbirth rates amongst affected foetuses, it would be expected that stillbirths attributable to neuraltube defects would also decrease by $41 \%$.

Maternal overweight and obesity are associated with an increased risk of stillbirth, preterm birth, congenital abnormalities, poor fetal growth and low birthweight $[55,68]$. Ten percent of stillbirths globally are estimated to be attributable to maternal obesity [1]. To date, there is limited evidence to inform interventions to reduce maternal obesity, either pre-conception or during pregnancy, to improve stillbirth outcomes $[69,70]$. This remains an important area for future research to improve the understanding of the biological pathways to increase risk, and which interventions may be amenable to clinical interventions.

\section{Fertility/ Family planning interventions}

The positive effects of contraception on maternal, newborn and child health have been well-documented [71]. Extremes of maternal age are associated with increased risk of stillbirth. Globally $6.7 \%$ of all stillbirths are estimated to be attributable to older maternal age ( $>35$ years) [1]. Adolescent pregnancy is also associated with increased risk, especially for girls under 16 years of age [72], but the magnitude of risk has not yet been quantified as studies frequently include these high risk groups with those 19-20 years who have the lowest biological risk. Short inter-pregnancy intervals are associated with poor perinatal outcomes, however the effect on stillbirths has yet to be quantified [73]. To date, there is insufficient evidence to support the inclusion of family planning interventions to reduce stillbirths in LiST. Currently, modelling stillbirths in LiST does not capture these effects as 
explained above. Moving forward and as the evidence base increases, inclusion of the potential effects of interventions such as reducing births in girls under 18 years of age, improved inter-pregnancy spacing and reducing unplanned pregnancies would be useful to planners and policy makers as they consider the potential full-impacts of their family planning programs.

\section{Environmental and lifestyle interventions}

Smoking is associated with an increased risk of stillbirth [74]. Worldwide smoking has been estimated to be attributable for $1.1 \%$ of stillbirths worldwide. Unless the trend of increasing rates of smoking among women in low- and middle-income countries (LMICs), especially in South America and parts of Asia, is reversed, smoking will likely become an important cause of preventable stillbirths in these regions [75]. Research has shown that pharmacological and psychosocial interventions can increase smoking cessation in pregnant women, however no effect has been shown on stillbirth rates, and these interventions are expensive and currently remain impractical in most high-burden settings [76, 77].

Household air pollution (HAP) exposure is known to be associated with multiple adverse health outcomes and increased mortality. Exposure is associated with an increased risk of stillbirth [78, 79]. Based on comparing stillbirth risk in observational studies of populations with low versus high HAP exposure, it is estimated that interventions to reduce HAP exposure could reduce stillbirths by $34 \%$ (OR $0.66,95 \%$ CI 0.54 to 0.81 ) [79]. In recent years, multiple studies have assessed interventions to reduce HAP and although the majority have shown effectiveness in reducing HAP levels, the declines have not reached the levels as recommended by the World Health Organization [80].

Violence against women, which remains highly prevalent worldwide, is associated with increased risk of stillbirth [81]. Although 30\% of ever-partnered women report having experienced sexual or physical violence, no specific estimates are available for pregnant women [82]. There is some evidence to suggest that advocacy interventions which aim to reduce exposure to violence may produce benefits [83], however, insufficient evidence is available to estimate the effectiveness of such interventions to reduce exposure and stillbirth rates as a result.

\section{Prevention of Rhesus disease}

Around $1 \%$ of stillbirths worldwide are estimated to be attributable to Rhesus (Rh) disease [1]. Antenatal screening for Rh negativity and anti-D immunoglobulin has been highly successful in reducing the incidence of haemolytic disease of the fetus and newborn and reducing stillbirths in countries where it has been implemented [84]. Anti-D has been shown to reduce iso-immunisation [85]. Whilst there is currently insufficient direct evidence to estimate the effectiveness of this intervention on stillbirths [85], the indirect evidence could be considered and may be used to inform future versions of LiST, especially for settings with high prevalence of Rh negativity and adequately strong health systems.

\section{Detection and management of HIV in pregnancy}

A recent review estimated that $0.7 \%$ of stillbirths in subSaharan Africa may be attributable to HIV infection [1], however the limitations of these data are noted. Roll-out of antiretroviral treatment (ART) to reduce the risk of mother-to-child transmission of HIV infection and the increased uptake of universal provision of maternal ART, in particular, are likely to affect this subgroup of stillbirths. However, as the attributable fraction of stillbirths that would benefit from this intervention is small and data to support the effect of ART on reduction in stillbirth risk are sparse, this intervention is not currently modelled in LiST.

\section{Modelling using stillbirth cause of death or risk data}

As detailed above, no comparable country-level causespecific stillbirth mortality estimates are currently available for most countries. The World Health Organization has recently published ICD-PM, the application of ICD10 to perinatal deaths in which it seeks to improve the data availability and comparability for perinatal deaths, including stillbirths, across countries [86]. However, it is likely to be many years before such data are readily available of sufficiently high quality across countries from all regions worldwide to allow global and country-level stillbirth cause-of-death estimates. Even in high-income regions with access and resources to conduct sophisticated investigations, the cause of stillbirth is unknown in around 30\% of cases [2]. Hence, updating and extending the approach of using the attributable mortality as the affected fraction to further interventions remains the most feasible approach at present.

\section{Conclusions}

LiST is a widely-used and valuable tool for modelling the impact of scaling-up interventions to reduce stillbirths across high-burden settings. Previous iterations of LiST have been hampered by a lack of robust data for some of the estimates of effectiveness, attributable mortality and coverage. Data for stillbirths remain incomplete but are improving and going forward, the LiST model will continue to evolve to reflect the improving data and expanded evidence base in order to provide an increasingly reliable tool for policy and programming purposes. 


\section{Additional files}

Additional file 1: Calculation of attributable stillbirths and affected fraction in the Lives Saved Tool. (DOCX 14 kb)

Additional file 2: Table of quality assessment for effectiveness estimates interventions effecting stillbirths included in the Lives Saved Tool in 2016. (DOCX $27 \mathrm{~kb}$ )

Additional file 3: Coverage assumptions for interventions impacting on stillbirths in the Lives Saved Tool. (DOCX 69 kb)

\section{Acknowledgments}

We acknowledge and thank Neff Walker for his support in including stillbirths within LiST, and for reviewing analyses and earlier drafts of this manuscript. This work was funded by a grant from the Bill \& Melinda Gates Foundation (JHU Grant 115621, Award Number OPP1084423) to support development of the Lives Saved Tool (LiST). HB received financial support for this analysis via a subcontract.

\section{Funding}

The publication costs for all supplement articles were funded by a grant from the Bill \& Melinda Gates Foundation (JHU Grant 115,621, Award Number OPP1084423 for the "Development and Use of the Lives Saved Tool $\left.(\operatorname{LiST})^{\prime \prime}\right)$.

\section{Availability of data and materials}

N/A

\section{About this supplement}

This article has been published as part of BMC Public Health Volume 17 Supplement 4, 2017: The Lives Saved Tool in 2017: Updates, Applications, and Future Directions. The full contents of the supplement are available online at https://bmcpublichealth.biomedcentral.com/articles/supplements/ volume-17-supplement-4.

\section{Authors' contributions}

$\mathrm{HB}$ and VC under took the analyses and wrote the first draft of the manuscript. JEL and ZB provided technical inputs into the initial design and refinements for the modelling of stillbirths in LiST. All authors contributed to manuscript and approved the final version.

\section{Ethics approval and consent to participate}

N/A.

\section{Consent for publication}

N/A.

\section{Competing interests}

The authors declare that they have no competing interests.

\section{Publisher's Note}

Springer Nature remains neutral with regard to jurisdictional claims in published maps and institutional affiliations.

\section{Author details}

${ }^{1}$ Maternal Adolescent Reproductive and Child Health (MARCH) Centre, London School of Hygiene \& Tropical Medicine, G11, Keppel Street, London WC1E 7HT, UK. ²Department of International Health, Johns Hopkins Bloomberg School of Public Health, 615 N. Wolfe Street, Room E5518, Baltimore, MD 21205, USA. ${ }^{3}$ Centre for Global Child Health, Hospital for Sick Children, Toronto, ON M5G 0A4, Canada.

\section{Published: 7 November 2017}

\section{References}

1. Lawn JE, Blencowe H, Waiswa P, Amouzou A, Mathers C, Hogan D, et al. Stillbirths: rates, risk factors, and acceleration towards 2030. Lancet (London, England). 2016;387(10018):587-603.
2. Flenady V, Wojcieszek AM, Middleton P, Ellwood D, Erwich JJ, Coory M, et al. Stillbirths: recall to action in high-income countries. Lancet. 2016:387(10019):691-702.

3. Graham WJ, Woodd S, Byass P, Filippi V, Gon G, Virgo S, et al. Diversity and divergence: the dynamic burden of poor maternal health. Lancet. 2016; 388(10056):2164-75.

4. de Bernis L, Kinney MV, Stones W, Ten Hoope-Bender P, Vivio D, Leisher SH, et al. Stillbirths: ending preventable deaths by 2030. Lancet. 2016; 387(10019):703-16.

5. Froen JF, Friberg IK, Lawn JE, Bhutta ZA, Pattinson RC, Allanson ER, et al. Stillbirths: progress and unfinished business. Lancet. 2016;387(10018):574-86.

6. World Health Organization. Improving measurement of the quality of maternal, newborn and child care in health facilities. 2014. http://apps.who. int/iris/bitstream/10665/128206/1/9789241507417_eng.pdf. Accessed 8th Aug 2016.

7. Stenberg K, Axelson H, Sheehan P, Anderson I, Gulmezoglu AM, Temmerman $\mathrm{M}$, et al. Advancing social and economic development by investing in women's and children's health: a new Global Investment Framework. Lancet (London, England). 2014;383(9925):1333-54.

8. Heazell AE, Siassakos D, Blencowe H, Burden C, Bhutta ZA, Cacciatore J, et al. Stillbirths: economic and psychosocial consequences. Lancet. 2016;387(10018):604-16.

9. UNICEF, The World Health Organization. Every Newborn: an action plan to end preventable newborn deaths. 2014. www.everynewborn.org.

10. Every Woman Every Child. Saving lives protecting futures: Progress Report on the Global Strategy for Women's and Children's Health 2010-2015. New York, 2015. http://everywomaneverychild.org/images/EWEC_Progress_ Report_FINAL_3.pdf. Accessed 9th Aug 2016.

11. Darmstadt GL, Bhutta ZA, Cousens S, Adam T, Walker N, de Bernis L. Evidence-based, cost-effective interventions: how many newborn babies can we save? Lancet. 2005;365(9463):977-88

12. Jones G, Steketee RW, Black RE, Bhutta ZA, Morris SS. How many child deaths can we prevent this year? Lancet. 2003;362(9377):65-71.

13. Hussain AA, Yakoob MY, Imdad A, Bhutta ZA. Elective induction for pregnancies at or beyond 41 weeks of gestation and its impact on stillbirths: a systematic review with meta-analysis. BMC Public Health. 2011; 11(Suppl 3):S5

14. Imdad A, Yakoob MY, Bhutta ZA. The effect of folic acid, protein energy and multiple micronutrient supplements in pregnancy on stillbirths. BMC Public Health. 2011:11(Suppl 3):S4.

15. Imdad A, Yakoob MY, Siddiqui S, Bhutta ZA. Screening and triage of intrauterine growth restriction (IUGR) in general population and high risk pregnancies: a systematic review with a focus on reduction of IUGR related stillbirths. BMC Public Health. 2011;11(Suppl 3):S1.

16. Jabeen M, Yakoob MY, Imdad A, Bhutta ZA. Impact of interventions to prevent and manage preeclampsia and eclampsia on stillbirths. BMC Public Health. 2011;11(Suppl 3):S6.

17. Syed M, Javed $H$, Yakoob MY, Bhutta ZA. Effect of screening and management of diabetes during pregnancy on stillbirths. BMC Public Health. 2011;11(Suppl 3):S2.

18. Ishaque S, Yakoob MY, Imdad A, Goldenberg RL, Eisele TP, Bhutta ZA Effectiveness of interventions to screen and manage infections during pregnancy on reducing stillbirths: a review. BMC Public Health. 2011; 11(Suppl 3):S3

19. Yakoob MY, Ali MA, Ali MU, Imdad A, Lawn JE, Van Den Broek N, et al. The effect of providing skilled birth attendance and emergency obstetric care in preventing stillbirths. BMC Public Health. 2011;11(Suppl 3):S7.

20. Bhutta ZA, Yakoob MY, Lawn JE, Rizvi A, Friberg IK, Weissman E, et al. Stillbirths: what difference can we make and at what cost? Lancet (London, England). 2011;377(9776):1523-38.

21. Pattinson R, Kerber K, Buchmann E, Friberg IK, Belizan M, Lansky S, et al. Stillbirths: how can health systems deliver for mothers and babies? Lancet. 2011;377(9777):1610-23.

22. Bhutta ZA, Das JK, Bahl R, Lawn JE, Salam RA, Paul VK, et al. Can available interventions end preventable deaths in mothers, newborn babies, and stillbirths, and at what cost? Lancet. 2014:384(9940):347-70.

23. Fischer Walker CL, Walker N. The Lives Saved Tool (LiST) as a model for diarrhea mortality reduction. BMC Med. 2014:12:70.

24. Garnett GP, Cousens S, Hallett TB, Steketee R, Walker N. Mathematical models in the evaluation of health programmes. Lancet. 2011; 378(9790):515-25. 
25. Walker N, Fischer-Walker C, Bryce J, Bahl R, Cousens S. Standards for CHERG reviews of intervention effects on child survival. Int J Epidemiol. 2010; 39(Suppl 1):i21-31.

26. Blencowe $\mathrm{H}$, Cousens $\mathrm{S}$, Jassir FB, Say L, Chou D, Mathers C, et al. National, regional, and worldwide estimates of stillbirth rates in 2015, with trends from 2000: a systematic analysis. Lancet Glob Health. 2016;4(2):e98-e108.

27. Aminu M, Unkels R, Mdegela M, Utz B, Adaji S, van den Broek N. Causes of and factors associated with stillbirth in low- and middle-income countries: a systematic literature review. BJOG. 2014;121(Suppl 4):141-53.

28. McClure EM, Goldenberg RL. Infection and stillbirth. Semin Fetal Neonatal Med. 2009;14(4):182-9.

29. Di Mario S, Say L, Lincetto O. Risk factors for stillbirth in developing countries: a systematic review of the literature. Sex Transm Dis. 2007;34(7 Suppl):S11-21.

30. Haider BA, Bhutta ZA. Multiple-micronutrient supplementation for women during pregnancy. Cochrane Database Syst Rev. 2015(11):Cd004905.

31. Anglim B, Mandiwanza T, Miletin J, Turner M, Kennelly MM. The natural history of neural tube defects in the setting of an Irish tertiary referral foetal medicine unit. J Obstet Gynaecol. 2016;36(1):19-23.

32. Castillo-Lancellotti C, Tur JA, Uauy R. Impact of folic acid fortification of flour on neural tube defects: a systematic review. Public Health Nutr. 2013:16(5):901-11.

33. De-Regil LM, Pena-Rosas JP, Fernandez-Gaxiola AC, Rayco-Solon P. Effects and safety of periconceptional oral folate supplementation for preventing birth defects. Cochrane Database Syst Rev. 2015(12):Cd007950.

34. De-Regil LM, Palacios C, Lombardo LK, Pena-Rosas JP. Vitamin D supplementation for women during pregnancy. Cochrane Database Syst Rev. 2016(1):Cd008873.

35. Hofmeyr GJ, Lawrie TA, Atallah AN, Duley L, Torloni MR. Calcium supplementation during pregnancy for preventing hypertensive disorders and related problems. Cochrane Database Syst Rev. 2014(6):Cd001059.

36. Makrides M, Crosby DD, Bain E, Crowther CA. Magnesium supplementation in pregnancy. Cochrane Database Syst Rev. 2014(4):Cd000937.

37. McCauley ME, van den Broek N, Dou L, Othman M. Vitamin A supplementation during pregnancy for maternal and newborn outcomes. Cochrane Database Syst Rev. 2015(10):Cd008666

38. Ota E, Mori R, Middleton P, Tobe-Gai R, Mahomed K, Miyazaki C, et al. Zinc supplementation for improving pregnancy and infant outcome. Cochrane Database Syst Rev. 2015(2):Cd000230.

39. Rumbold A, Ota E, Hori H, Miyazaki C, Crowther CA. Vitamin E supplementation in pregnancy. Cochrane Database Syst Rev. 2015(9): Cd004069

40. Rumbold A, Ota E, Nagata C, Shahrook S, Crowther CA. Vitamin C supplementation in pregnancy. Cochrane Database Syst Rev. 2015(9):Cd004072.

41. Imdad A, Bhutta ZA. Maternal nutrition and birth outcomes: effect of balanced protein-energy supplementation. Paediatr Perinat Epidemiol. 2012; 26(Suppl 1):178-90.

42. Ota E, Hori H, Mori R, Tobe-Gai R, Farrar D. Antenatal dietary education and supplementation to increase energy and protein intake. Cochrane Database Syst Rev. 2015(6):Cd000032

43. The World Bank. World Bank indicators from http://data.worldbank.org/ indicator. Accessed 30th June 2016

44. Dellicour S, Tatem AJ, Guerra CA, Snow RW, ter Kuile FO. Quantifying the number of pregnancies at risk of malaria in 2007: a demographic study. PLoS Med. 2010;7(1):e1000221.

45. Gamble C, Ekwaru JP, ter Kuile FO. Insecticide-treated nets for preventing malaria in pregnancy. Cochrane Database Syst Rev. 2006(2):Cd003755.

46. Radeva-Petrova D, Kayentao K, ter Kuile FO, Sinclair D, Garner P. Drugs for preventing malaria in pregnant women in endemic areas: any drug regimen versus placebo or no treatment. Cochrane Database Syst Rev. 2014(10):Cd000169.

47. Guerra CA, Gikandi PW, Tatem AJ, Noor AM, Smith DL, Hay SI, et al. The limits and intensity of Plasmodium falciparum transmission: implications for malaria control and elimination worldwide. PLoS Med. 2008;5(2):e38.

48. Wijesooriya NS, Rochat RW, Kamb ML, Turlapati P, Temmerman M, Broutet N, et al. Global burden of maternal and congenital syphilis in 2008 and 2012: a health systems modelling study. Lancet Glob Health. 2016;4(8):e525-33.

49. Gomez GB, Kamb ML, Newman LM, Mark J, Broutet N, Hawkes SJ. Untreated maternal syphilis and adverse outcomes of pregnancy: a systematic review and meta-analysis. Bull World Health Organ. 2013;91(3):217-26.

50. Blencowe H, Cousens S, Kamb M, Berman S, Lawn JE. Lives saved tool supplement detection and treatment of syphilis in pregnancy to reduce syphilis related stillbirths and neonatal mortality. BMC Public Health. 2011;11(Suppl 3):S9.
51. Ng M, Fleming T, Robinson M, Thomson B, Graetz N, Margono C, et al Global, regional, and national prevalence of overweight and obesity in children and adults during 1980-2013: a systematic analysis for the global burden of disease study 2013. Lancet. 2014;384(9945):766-81.

52. Mwanri AW, Kinabo J, Ramaiya K, Feskens EJ. Gestational diabetes mellitus in sub-Saharan Africa: systematic review and metaregression on prevalence and risk factors. Tropical Med Int Health. 2015;20(8):983-1002.

53. Tutino GE, Tam WH, Yang X, Chan JC, Lao TT, Ma RC. Diabetes and pregnancy: perspectives from Asia. Diabet Med. 2014;31(3):302-18.

54. Jain R, Davey S, Davey A, Raghav SK, Singh JV. Can the management of blood sugar levels in gestational diabetes mellitus cases be an indicator of maternal and fetal outcomes? The results of a prospective cohort study from India. J Fam Community Med. 2016;23(2):94-9.

55. Flenady V, Koopmans L, Middleton P, Froen JF, Smith GC, Gibbons K, et al. Major risk factors for stillbirth in high-income countries: a systematic review and meta-analysis. Lancet. 2011;377(9774):1331-40.

56. Abalos E, Cuesta C, Grosso AL, Chou D, Say L. Global and regional estimates of preeclampsia and eclampsia: a systematic review. Eur J Obstet Gynecol Reprod Biol. 2013:170(1):1-7.

57. Gulmezoglu AM, Crowther CA, Middleton P, Heatley E. Induction of labour for improving birth outcomes for women at or beyond term. Cochrane Database Syst Rev. 2012;6:CD004945.

58. Hedegaard M, Lidegaard O, Skovlund CW, Morch LS, Hedegaard M. Reduction in stillbirths at term after new birth induction paradigm: results of a national intervention. BMJ Open. 2014;4(8):e005785.

59. Norwitz ER, Snegovskikh W, Caughey AB. Prolonged pregnancy: when should we intervene? Clin Obstet Gynecol. 2007;50(2):547-57.

60. Hofmeyr GJ, Haws RA, Bergstrom S, Lee AC, Okong P, Darmstadt GL, et al. Obstetric care in low-resource settings: what, who, and how to overcome challenges to scale up? Int J Gynaecol Obstet. 2009;107(Suppl 1):S21-44. S-5

61. World Health Organization, UNFPA, UNICEF, Mailman School of Public Health Averting Maternal death and Disability, (AMDD). Monitoring emergency obstetric care. 2009. http://www.who.int/reproductivehealth/ publications/monitoring/9789241547734/en/. Accessed 15th June 2016.

62. Goldenberg RL, McClure EM, Bann CM. The relationship of intrapartum and antepartum stillbirth rates to measures of obstetric care in developed and developing countries. Acta Obstet Gynecol Scand. 2007;86(11):1303-9.

63. Betran AP, Torloni MR, Zhang J, Ye J, Mikolajczyk R, Deneux-Tharaux C, et al. What is the optimal rate of caesarean section at population level? A systematic review of ecologic studies. Reprod Health. 2015;12(1):57.

64. Robert Peter J, Ho JJ, Valliapan J, Sivasangari S. Symphysial fundal height (SFH) measurement in pregnancy for detecting abnormal fetal growth. Cochrane Database Syst Rev. 2015(9):Cd008136.

65. Heazell AE, Whitworth M, Duley L, Thornton JG. Use of biochemical tests of placental function for improving pregnancy outcome. Cochrane Database Syst Rev. 2015(11):Cd011202.

66. Alfirevic Z, Stampalija T, Gyte GM. Fetal and umbilical Doppler ultrasound in high-risk pregnancies. Cochrane Database Syst Rev. 2013(11):Cd007529.

67. Atta CA, Fiest KM, Frolkis AD, Jette N, Pringsheim T, St Germaine-Smith C, et al. Global birth prevalence of spina bifida by folic acid fortification status: a systematic review and meta-analysis. Am J Public Health. 2016;106(1):e24-34

68. Marchi J, Berg M, Dencker A, Olander EK, Begley C. Risks associated with obesity in pregnancy, for the mother and baby: a systematic review of reviews. Obes Rev. 2015;16(8):621-38.

69. Opray N, Grivell RM, Deussen AR, Dodd JM. Directed preconception health programs and interventions for improving pregnancy outcomes for women who are overweight or obese. Cochrane Database Syst Rev. 2015(7):Cd010932.

70. Furber CM, McGowan L, Bower P, Kontopantelis E, Quenby S, Lavender T. Antenatal interventions for reducing weight in obese women for improving pregnancy outcome. Cochrane Database Syst Rev. 2013(1):Cd009334.

71. Cleland J, Conde-Agudelo A, Peterson H, Ross J, Tsui A. Contraception and health. Lancet. 2012:380(9837):149-56.

72. Althabe F, Moore UL, Gibbons L, Berrueta M, Goudar SS, Chomba E, et al. Adverse maternal and perinatal outcomes in adolescent pregnancies: The Global Network's Maternal Newborn Health Registry study. Reprod Health. 2015:12(Suppl 2):S8.

73. Kozuki N, Walker N. Exploring the association between short/long preceding birth intervals and child mortality: using reference birth interval children of the same mother as comparison. BMC Public Health. 2013;13(Suppl 3):S6.

74. Marufu TC, Ahankari A, Coleman T, Lewis S. Maternal smoking and the risk of still birth: systematic review and meta-analysis. BMC Public Health. 2015;15:239. 
75. Bilano V, Gilmour S, Moffiet T, d'Espaignet ET, Stevens GA, Commar A, et al. Global trends and projections for tobacco use, 1990-2025: an analysis of smoking indicators from the WHO comprehensive information systems for tobacco control. Lancet. 2015:385(9972):966-76.

76. Coleman T, Chamberlain C, Davey MA, Cooper SE, Leonardi-Bee J. Pharmacological interventions for promoting smoking cessation during pregnancy. Cochrane Database Syst Rev. 2015(12):Cd010078.

77. Chamberlain C, O'Mara-Eves A, Oliver S, Caird JR, Perlen SM, Eades SJ, et al. Psychosocial interventions for supporting women to stop smoking in pregnancy. Cochrane Database Syst Rev. 2013(10):Cd001055.

78. Amegah AK, Quansah R, Jaakkola JJ. Household air pollution from solid fuel use and risk of adverse pregnancy outcomes: a systematic review and meta-analysis of the empirical evidence. PLoS One. 2014;9(12):e113920.

79. Bruce NG, Dherani MK, Das JK, Balakrishnan K, Adair-Rohani H, Bhutta ZA, et al. Control of household air pollution for child survival: estimates for intervention impacts. BMC Public Health. 2013;13(Suppl 3):S8.

80. Thomas E, Wickramasinghe K, Mendis S, Roberts N, Foster C. Improved stove interventions to reduce household air pollution in low and middle income countries: a descriptive systematic review. BMC Public Health. 2015;15:650.

81. Han A, Stewart DE. Maternal and fetal outcomes of intimate partner violence associated with pregnancy in the Latin American and Caribbean region. Int J Gynaecol Obstet. 2014;124(1):6-11.

82. World Health Organization. Global Health Observatory. http://www.whoint/ gho/en/. Accessed 7th Aug 2016.

83. Rivas C, Ramsay J, Sadowski L, Davidson LL, Dunne D, Eldridge S, et al. Advocacy interventions to reduce or eliminate violence and promote the physical and psychosocial well-being of women who experience intimate partner abuse. Cochrane Database Syst Rev. 2015(12):Cd005043.

84. Bhutani VK, Zipursky A, Blencowe H, Khanna R, Sgro M, Ebbesen F, et al. Neonatal hyperbilirubinemia and Rhesus disease of the newborn: incidence and impairment estimates for 2010 at regional and global levels. Pediatr Res. 2013;74(Suppl 1):86-100.

85. McBain RD, Crowther CA, Middleton P. Anti-D administration in pregnancy for preventing Rhesus alloimmunisation. Cochrane Database Syst Rev. 2015(9):Cd000020.

86. World Health Organization. The WHO Application of ICD-10 to deaths during the perinatal period: ICD-PM. 2015. http://apps.who.int/iris/bitstream/ 10665/249515/1/9789241549752-eng.pdf. Accessed 26th Aug 2016.

87. Tako EA, Zhou A, Lohoue J, Leke R, Taylor DW, Leke RF. Risk factors for placental malaria and its effect on pregnancy outcome in Yaounde, Cameroon. Am J Trop Med Hyg. 2005;72(3):236-42.

88. van Geertruyden JP, Thomas F, Erhart A, D'Alessandro U. The contribution of malaria in pregnancy to perinatal mortality. Am J Trop Med Hyg. 2004;71(2 Suppl):35-40.

89. Newman L, Rowley J, Vander Hoorn S, Wijesooriya NS, Unemo M, Low N, et al. Global Estimates of the Prevalence and Incidence of Four Curable Sexually Transmitted Infections in 2012 Based on Systematic Review and Global Reporting. PLoS One. 2015;10(12):e0143304.

90. McDermott J, Steketee R, Wirima J. Perinatal mortality in rural Malawi. Bull World Health Organ. 1996;74(2):165-71.

91. International Diabetes Federation. IDF Diabetes, 7 ed. Brussels, Belgium: International Diabetes Federation. http://www.diabetesatlas.org. 2015.

92. ACOG Practice Bulletin. Clinical management guidelines for obstetriciangynecologists. Number 30, September 2001 (replaces Technical Bulletin Number 200, December 1994). Gestational diabetes. Obstet Gynecol. 2001; 98(3):525-38.

93. Dolea C, Abu Zahr C. Global burden of hypertensive disorders of pregnancy in the year 2000. Geneva: World Health Organization. 2003.

94. Shea KM, Wilcox AJ, Little RE. Postterm delivery: a challenge for epidemiologic research. Epidemiology (Cambridge, Mass). 1998;9(2):199-204.

\section{Submit your next manuscript to BioMed Central and we will help you at every step:}

- We accept pre-submission inquiries

- Our selector tool helps you to find the most relevant journal

- We provide round the clock customer support

- Convenient online submission

- Thorough peer review

- Inclusion in PubMed and all major indexing services

- Maximum visibility for your research

Submit your manuscript at www.biomedcentral.com/submit
Biomed Central 